\section{Estudo \\ cobebate}

em Testão

Planejamento
Revista Estudo \& Debate, Lajeado, v. 23, n. 2, 2016. ISSN 1983-036X DOI: http://dx.doi.org/10.22410/issn.1983-036X.v23i2a2016.1075

\title{
A APICULTURA EM RONDÔNIA (AMAZÔNIA LEGAL): ESTUDO DE CASO SOBRE O ARRANJO PRODUTIVO LOCAL DA APICULTURA NO CONE SUL
}

José Arilson de Souza ${ }^{1}$, Emanuel Fernando Maia de Souza ${ }^{2}$, Anna Frida Hatsue Modro ${ }^{3}$,

Wellington Silva Porto ${ }^{4}$, Deyvison de Lima Oliveira ${ }^{5}$

\begin{abstract}
Resumo: Este artigo apresenta uma visão reflexiva da realidade da apicultura em um estado da Amazônia Legal (Rondônia), na perspectiva das políticas públicas previstas no planejamento oficial e sua relação com abordagens da sustentabilidade. Para tanto, parte de uma visão geral da produção apícola no Brasil e no mundo, apresentando características dessa produção nos Estados brasileiros. Apresenta uma visão geral da representatividade da produção de mel do Brasil no cenário mundial, o ranking de produção dos estados brasileiros com base no ano de 2012 e a realidade da apicultura no estado de Rondônia, apontando as políticas públicas previstas por meio do planejamento plurianual e a sua relação com algumas abordagens sobre a sustentabilidade.
\end{abstract}

Palavras-chave: Mel. Sustentabilidade. Agronegócio. Desenvolvimento econômico.

\section{THE BEEKEEPING IN THE STATE OF RONDÔNIA (LEGAL AMAZON REGION): CASE STUDY ABOUT THE CLUSTER OF THE BEEKEEPING PRODUCTION IN THE SOUTHERN CONE}

\begin{abstract}
This article presents a reflective view on the reality of beekeeping in a state of the Legal Amazon region (Rondônia), from the perspective of the public policies established in the official planning and its relation with the approaches to sustainability. In order to do so, this study is based on an overview of the beeking production in Brazil and throughout the world, presenting the characteristics of such production in the Brazilian states.
\end{abstract}

1 Programa De Doutorado Desenvolvimento Regional E Meio Ambiente.

2 Doutor em Fitotecnia pela Universidade Federal de Viçosa. Professor da Universidade Federal de Rondônia.

3 Doutora em Entomologia pela Escola Superior de Agricultura Luiz Queiroz. Professor da Universidade Federal de Rondônia.

4 Mestre em Engenharia Produção pela Universidade Federal de Santa Catarina. Professor da Universidade Federal de Rondônia.

5 Doutor em Administração pela Universidade Federal Rio Grande do Sul. Professor da Universidade Federal de Rondônia. 
The article presents an overview of the representativity of Brazil's honey production in the world, the ranking of the production of the Brazilian states based on the year of 2012 and the reality of beekeeping in the state of Rondônia, pointing out the public policies established in the multi-year planning and its relationship with some approaches to sustainability.

Keywords: Honey. Sustainability. Agribusiness. Economic development.

\section{INTRODUÇÁO}

A apicultura, segundo Camargo (1972), é caraterizada pela exploraçáo econômica e racional da abelha Apis mellifera, sendo introduzida pela primeira vez no Brasil em 1839. Essa atividade, conforme destaca Silva e Peixe (2008), atinge a sua importância por possibilitar a geração de emprego e renda, favorecer na atividade rural uma diversificação de negócios, proporcionando a partir destes relevantes benefícios sociais, econômicos e ecológicos. $\mathrm{Na}$ atividade apícola, o principal produto comercializado é o mel, todavia existe a possibilidade da produção de pólen, própolis, geleia real, cera e apitoxina.

Como destaca Lima (2005), a apicultura é economicamente viável dado a sua rentabilidade reconhecida, consistente pelo conceito de responsabilidade ecológica, e pode ser tratada como atividade acessível e com amplas possibilidades de implementação, pois pode ser desenvolvida em, praticamente, todo o espaço geográfico do país, que possui condições de solo e clima favorável e uma vegetação exuberante e rica em floradas, sendo uma atividade sustentável e de grande importância econômica.

Desde que a Comissão Mundial sobre o Meio Ambiente da Organização das Naçóes Unidas (ONU) publicou seu relatório em abril de 1987, sob a denominação de "Nosso futuro comum", o conceito de desenvolvimento sustentável tem sido alicerçado nos aspectos que visam a atender necessidades do presente sem comprometer a capacidade das futuras geraçóes atenderem às suas. Esse documento aponta para a responsabilidade de todos os povos quanto a açóes políticas que devem ser empreendidas visando a administrar os recursos ambientais de forma a garantir o progresso humano continuado e a sobrevivência da humanidade (DONAIRE, 1995).

$\mathrm{O}$ modelo de desenvolvimento industrial, em mais de um século, gerou alguns impactos de alta relevância: aquecimento global, redução da camada de ozônio, poluiçáo do ar e água, erosão dos solos e devastação das florestas, sendo esses impactos amplamente reconhecidos como problemas ambientais globais que exigem soluçôes imediatas, como aponta Subhabrata (2003). Esses impactos tornam-se ainda mais severos quando ocorrem em regiốes de grande biodiversidade, como é o caso da Amazônia. Sendo assim, a preocupação com questôes ambientais é pertinente, gerando contínuos estudos e posicionamentos que envolvem o tema sustentabilidade.

Em busca de alternativas produtivas que possibilitem uma equação de equilíbrio entre os aspectos econômicos e ambientais, como aponta Souza (2007), a apicultura brasileira reúne requisitos que a coloca num elevado potencial de inclusão, pois, sob os pontos de vista ambiental, econômico e social, é capaz de gerar ocupaçôes "socialmente justas", desde que devidamente apoiadas pelo poder público ou iniciativas privadas. 
Pela sua natureza, a apicultura é uma atividade conservadora das espécies, afirma Guimarães (1989). A atividade apícola harmoniza-se com a preservação ambiental, diferindo, portanto, da maioria das atividades rurais que tendem a gerar impactos negativos no ambiente, e torna-se uma das poucas atividades agropecuárias que atende os requisitos da sustentabilidade: o econômico porque gera renda para os agricultores, o social porque utiliza a mão de obra familiar no campo, diminuindo o êxodo rural, e o ecológico porque exige dos apicultores a conservação de matas e a racionalização do uso de agrotóxicos nas proximidades dos apiários, e ainda as abelhas contribuem para a produção agropecuária com a polinização dos cultivos.

Em Rondônia, a apicultura teve seu início durante a colonização do Estado, influenciada, principalmente, por migrantes do sul do país, recebendo na década de 1980 forte apoio por parte do governo do Estado por meio de capacitação técnica e investimentos em infraestrutura. $\mathrm{O}$ processo de desenvolvimento na forma de arranjo produtivo local - APL recebeu novo impulso a partir do ano de 2004 com investimentos que o Serviço de Apoio às Micro e Pequenas Empresas (SEBRAE/RO) e parceiros fizeram no setor por meio do Projeto Apicultura Integrada e Sustentável (PROAPIS) promovendo um amplo diagnóstico da atividade no Estado.

Os apicultores do estado de Rondônia, visando ao alinhamento competitivo ao cenário nacional, têm se organizado em cooperativas e associaçóes. As cooperativas foram criadas com o propósito de estruturar a comercialização coletiva da produção, organizar a infraestrutura física e gerencial, além de consolidar o desenvolvimento do registro da marca “MEL SILVESTRE DA AMAZÔNIA" (SOUZA, 2010).

A apicultura em Rondônia tem, no entanto, apresentado um crescimento acanhado quando comparado com outras regióes do país. A atividade é impactada por problemas como atravessadores, limitaçóes de créditos para o segmento, ausências de informaçóes técnicas e dificuldade de armazenamento, conforme destacado por Souza (2010). Essa realidade torna-se relevante para o estudo inovador do cenário de políticas públicas voltadas para o segmento, no que tange ao desenvolvimento de arranjos produtivos locais apícolas.

Assim, objetiva-se apresentar uma visão reflexiva da realidade da apicultura em um estado da Amazônia Legal (Rondônia), na perspectiva das políticas públicas previstas no planejamento oficial e sua relação com abordagens da sustentabilidade. Para tanto, parte-se de uma visão geral da produção apícola no Brasil e no mundo, apresentando características dessa produção nos Estados brasileiros.

\section{REFERENCIAL TEÓRICO}

Nesta seção são abordados aspectos teóricos relacionados à atividade da apicultura, sustentabilidade, arranjo produtivo e políticas para o segmento apícola.

\subsection{Apicultura: conceito e a sustentabilidade}

A apicultura, segundo Vieira (1986), é a arte ou ciência de criar as melhores linhagens de abelhas para que, no menor tempo, nos forneçam os melhores produtos, pelos menores 
preços (custos), para se obter maiores lucros. A apicultura possibilita um diferencial, inclusive sobre outras criaçôes, por exigir pequenas áreas para instalar os apiários; possibilita a polinização em massa e a multiplicação das colheitas agrícolas; há mercados internos e externos para toda a produçáo; seus produtos alcançam elevados preços e, ainda, nesta atividade, pode ser aproveitada com grande eficiência a mão de obra menos especializada.

Essa atividade, como destaca LIMA (2005), é economicamente viável dado a sua rentabilidade reconhecida, consistente pelo conceito de responsabilidade ecológica e pode ser tratada como atividade acessível e com amplas possibilidades, pois pode ser desenvolvida em, praticamente, todo o espaço geográfico do país, que possui condiçôes favoráveis à produçâo diversificada de produtos apícolas, sendo uma atividade sustentável e de grande importância econômica.

O elemento polinização na atividade apícola representa relevante aspecto de sustentabilidade. Estima-se, como destaca Mcgregor (1976), que 90\% das 250 mil espécies de plantas e flores e $80 \%$ dos vegetais superiores de interesse econômico sejam polinizadas especialmente por insetos, sendo as abelhas consideradas as mais eficientes.

Desde que a Comissão Mundial sobre o Meio Ambiente da Organização das Naçóes Unidas (ONU) publicou seu relatório em abril de 1987, sob a denominaçấo de "Nosso futuro comum", o conceito de desenvolvimento sustentável tem sido alicerçado nos aspectos que visam a atender as necessidades do presente sem comprometer a capacidade das futuras geraçôes atenderem às suas. Esse documento aponta para a responsabilidade de todos os povos quanto a açóes políticas que devem ser empreendidas visando a administrar os recursos ambientais de forma a garantir o progresso humano continuado e a sobrevivência da humanidade (DONAIRE, 1995).

A sustentabilidade não é, e nunca será, uma noção de natureza precisa, discreta, analítica, ou aritmética, como qualquer positivista desejaria que fosse. Existem, contudo, agradáveis motivos para uma adoção do adjetivo "sustentável", haja vista sua capacidade de atingir um abrangente atendimento a necessidade humana (VEIGA 2012).

O modelo de desenvolvimento industrial, em mais de um século, gerou alguns impactos de alta relevância: aquecimento global, redução da camada de ozônio, poluiçáo do ar e água, erosão dos solos e devastação das florestas, sendo estes impactos amplamente reconhecidos como problemas ambientais globais que exigem soluçôes imediatas, como aponta Subhabrata (2003). Esses impactos tornam-se ainda mais severos quando ocorrem em regiôes de grande biodiversidade, como é o caso da Amazônia brasileira. Sendo assim, a preocupação com questóes ambientais é pertinente, gerando continuamente estudos e posicionamentos que envolvem o tema sustentabilidade.

Em busca de alternativas produtivas que possibilitem uma equação de equilíbrio entre os aspectos econômicos e ambientais, como aponta Souza (2007), a apicultura brasileira reúne requisitos que a coloca num elevado potencial de inclusão, pois, sob os pontos de vista ambiental, econômico e social, é capaz de gerar ocupaçôes "socialmente justas", desde que devidamente apoiadas pelo poder público ou iniciativas privadas.

Pela sua natureza, a apicultura é uma atividade conservadora das espécies (GUIMARÁES 1989). A atividade apícola harmoniza-se com a conservação ambiental, 
com poucos impactos negativos diferindo, portanto, da maioria das atividades rurais que tendem a gerar impactos negativos no ambiente, principalmente pela mudança no uso dos solos. A apicultura pode ser considerada uma das poucas atividades agropecuárias que atende os requisitos da sustentabilidade: o econômico porque gera renda para os agricultores - direta e indiretamente com os serviços de polinizaçáo; o social porque utiliza a máo de obra familiar no campo, reduzindo a pressão para o êxodo rural; e o ecológico porque exige dos apicultores a conservação de matas e a racionalização do uso de agrotóxicos nas proximidades dos apiários, e ainda as abelhas contribuem para a produção agropecuária com a polinização dos cultivos.

Lima (2005) trata da apicultura como uma atividade economicamente viável, com fortes características ecológicas e ambientais, atividade capaz de integrar as famílias envolvidas no processo, podendo equilibrar a tradição com a inovação. Siena, Muller e Fachinello (2012) destacam ainda que há uma forma complexa de interação entre essas dimensóes e que o equilíbrio entre elas é dinâmico, e a compreensão de que os recursos naturais são finitos é o primeiro passo para a realização de um desenvolvimento sustentável.

Considerando critérios multidimensionais para avaliação da sustentabilidade e adaptando-o às interfaces e peculiaridades da apicultura brasileira, temos que a atividade apícola no meio rural apresenta critérios que contemplam todas as dimensóes, a saber: social, econômica, ambiental, ecológica, territorial, política e cultural, tornando-se assim uma atividade com evidente potencial de sustentabilidade (TABELA 1).

Tabela 1 - Dimensóes, critérios e objetivos da sustentabilidade na atividade apícola

\begin{tabular}{|c|c|c|}
\hline \multicolumn{3}{|c|}{ DIMENSÓES DA SUSTENTABILIDADE NA ATIVIDADE APÍCOLA* } \\
\hline DIMENSÁO & CRITÉRIOS & OBJETIVOS \\
\hline Social & $\begin{array}{l}\text { Geraçáo de emprego com qualidade de vida. } \\
\text { Permanência de jovens e adultos no campo, } \\
\text { diminuindo os impactos causados pela falta de } \\
\text { oportunidades em comunidades suburbanas, prezando } \\
\text { pela igualdade social em questóes de gênero, etária } \\
\text { e classe. Fortalecimento da agricultura familiar e da } \\
\text { qualidade de vida no meio rural. Justa distribuiçáo de } \\
\text { renda. }\end{array}$ & $\begin{array}{l}\text { Reduzir as } \\
\text { desigualdades sociais. }\end{array}$ \\
\hline Econômica & $\begin{array}{l}\text { Incentivo à segurança alimentar. Modernização dos } \\
\text { instrumentos de produção. Autonomia na pesquisa } \\
\text { científica e tecnológica. Fluxo de investimentos } \\
\text { públicos e privados. Absorçáo dos custos ambientais. } \\
\text { Potencial para utilizaçáo de áreas náo manejadas e uso } \\
\text { múltiplo de florestas nativas e plantadas. Potencial de } \\
\text { renda principal ou alternativa na agricultura familiar. }\end{array}$ & $\begin{array}{l}\text { Aumentar a produção } \\
\text { e a riqueza social com } \\
\text { autonomia. }\end{array}$ \\
\hline
\end{tabular}




\begin{tabular}{|c|c|c|}
\hline \multicolumn{3}{|c|}{ DIMENSÓES DA SUSTENTABILIDADE NA ATIVIDADE APÍCOLA* } \\
\hline DIMENSÃO & CRITÉRIOS & OBJETIVOS \\
\hline Ambiental & $\begin{array}{l}\text { Respeito à capacidade de carga dos ecossistemas e à } \\
\text { capacidade da natureza para absorver e recuperar-se das } \\
\text { agressóes. Incentivo à racionalizaçáo ou diminuiçáo do } \\
\text { uso de agrotóxicos no meio rural. Geração de serviços } \\
\text { ambientais com a polinização natural e dirigida de } \\
\text { cultivos agrícolas ou florestas nativas. }\end{array}$ & $\begin{array}{l}\text { Melhorar e/ou manter } \\
\text { o estado de conservaçáo } \\
\text { dos ecossistemas. }\end{array}$ \\
\hline Ecológica & $\begin{array}{l}\text { Produção respeitando os ciclos ecológicos dos } \\
\text { ecossistemas. Apoio às ações de manutenção de áreas } \\
\text { de conservaçáo. Prudência no uso de recursos naturais } \\
\text { renováveis e não renováveis. }\end{array}$ & $\begin{array}{l}\text { Preservar o potencial do } \\
\text { capital natural na sua } \\
\text { produção de recursos. } \\
\text { Reduzir das pressóes por } \\
\text { conversão de novas áreas. } \\
\text { Manter a paisagem. } \\
\end{array}$ \\
\hline $\begin{array}{l}\text { Territorial (ou } \\
\text { Espacial) }\end{array}$ & $\begin{array}{l}\text { Respeito às peculiaridades ambientais e à capacidade } \\
\text { de suporte da natureza, cotejamento entre crescimento } \\
\text { econômico, taxas de aumento de produtividade e } \\
\text { crescimento populacional, sua composiçáo etária } \\
\text { e outras variáveis demográficas. Desconcentração } \\
\text { espacial (de atividades; de populaçáo). }\end{array}$ & $\begin{array}{l}\text { Distribuir } \\
\text { equalitariamente } \\
\text { processos, serviços, bens } \\
\text { e pessoas no território. } \\
\text { Formar e manter } \\
\text { identidades territoriais } \\
\text { dos apicultores. }\end{array}$ \\
\hline Política & $\begin{array}{l}\text { Construção da cidadania. Incentivo à organização } \\
\text { social. Aumento do capital social, governança e } \\
\text { participação. }\end{array}$ & $\begin{array}{l}\text { Incorporar plenamente } \\
\text { os indivíduos } \\
\text { no processo de } \\
\text { desenvolvimento. } \\
\end{array}$ \\
\hline Cultural & $\begin{array}{l}\text { Manutenção da diversidade e integração nacional ao } \\
\text { longo do tempo. Respeito aos direitos das minorias. } \\
\text { Adaptaçóes a cada ecossistema. Respeito à formação } \\
\text { cultural comunitária e tradicional do apicultor sem, } \\
\text { contudo, limitar as iniciativas de inovaçáo para a } \\
\text { atividade. }\end{array}$ & $\begin{array}{l}\text { Promover o equilíbrio } \\
\text { entre respeito à tradição } \\
\text { e inovação, autonomia e } \\
\text { autoconfiança aliada com } \\
\text { abertura para o mundo. }\end{array}$ \\
\hline
\end{tabular}

Fonte: Adaptado de Siena, Muller, Fachinello (2012).

Nesse sentido há de se observar que as políticas públicas do estado de Rondônia precisam estar sincronizadas com as pesquisas sobre a apicultura e sustentabilidade. Para isso sugere-se a observação dos elementos sustentáveis e as suas dimensóes que categorizam a apicultura como atividade que pode contribuir para redução das desigualdades sociais (sustentabilidade social); melhoria da qualidade ambiental e da manutenção do potencial do capital natural observando a preservação que é própria da atividade apícola (sustentabilidade ambiental e ecológica); equilíbrio do ambiente com a equiparação da atividade rural, observando que a maior parte das famílias envolvidas com a apicultura estão localizadas nos espaços rurais e urbanos (sustentabilidade territorial); possibilidade de inserçáo do apicultor no processo de desenvolvimento (sustentabilidade política); equilíbrio entre respeito à tradição do apicultor e inovação exigida pela apicultura focando a sua inserção no mercado mundial (sustentabilidade cultural). 


\subsection{A Apicultura e seu desenvolvimento}

Para Souza (2007), a apicultura brasileira começou oficialmente no século XIX, quando o Imperador Pedro II autorizou, pelo Decreto no 72, de 12 de julho de 1839, o padre Antonio José Pinto Carneiro a trazer abelhas da Europa e da costa da África, conforme segue:

DECRETO No 72, de 12 de julho de 1839

Autoriza o Governo a conceder ao Padre Antonio José Pinto Carneiro privilégio exclusivo pelo espaço de dez anos, a fim de importar abelhas da Europa ou Costa da África, para o Município da Côrte, Província do Rio de Janeiro.

O Regente em nome do Imperador o Senhor Dom Pedro segundo tem sancionado e manda que se execute a Resolução seguinte da Assembléia Geral Legislativa:

Art. $1^{\circ}$ - O Governo fica autorizado a conceder ao Padre Antonio José Pinto Carneiro, privilégio exclusivo pelo espaço de dez anos, a fim de importar abelhas da Europa ou da Costa da África para o Município da Côrte e Província do Rio de Janeiro.

Art. $2^{\circ}$ - Este privilégio cessará, se dentro de um ano náo tiver principio o estabelecimento das colméias no Município da Côrte.

Francisco de Paula de Almeida Albuquerque, Ministro e Secretário de Estado dos Negócios da Justiça, encarregado interinamente do Império, assim o tenha entendido e faça executar com os despachos necessários. Palácio do Rio de Janeiro, em doze de julho de mil oitocentos e trinta e nove, décimo oitavo da Independência e do Império.

Para a Confederaçáo Brasileira de Apicultura - CBA, esse decreto é, sem dúvida, a certidão de nascimento da Apicultura na Nação Brasileira, porque até então não havia abelhas da espécie Apis mellifera no Brasil.

Com a introdução da abelha africana (Apis Mellifera scutellata) em 1956, a apicultura brasileira tomou um novo rumo quando, por um acidente, essas abelhas escaparam do apiário experimental e passaram a se acasalar com as abelhas de raça europeia, formando um híbrido natural chamado de abelha africanizada. A alta defensividade dessas abelhas africanizadas causou, inicialmente, um grande problema no manejo dos apiários, e muitos apicultores abandonaram a atividade. Somente com o desenvolvimento de técnicas adequadas às abelhas africanizadas, nos anos 70 , a apicultura passou a crescer e se expandiu para as regiōes Norte, Nordeste e Centro-Oeste, destaca Souza (2010).

Capaz de causar impactos positivos, a apicultura é uma atividade social, ambiental e econômica, além de contribuir para a manutenção e preservação dos ecossistemas existentes. A cadeia produtiva da apicultura propicia a geração de inúmeros postos de trabalho e fluxo de renda, principalmente no ambiente familiar, sendo determinante na melhoria da qualidade de vida, preservaçáo do meio ambiente, melhoria da renda familiar e fixação do homem no meio rural (PEREIRA et al., 2002, apud MACHADO e SILVA, 2010).

A atividade apícola tem forte conotação ambiental, comprovadamente rentável, que pode ser desenvolvida em diversos espaços geográficos, quer seja em áreas de cerrado (campos sujos), caatingas ou quer seja em solos com clima favorável e uma vegetação rica em 
floradas. É uma atividade sustentável e de grande importância econômica. No contexto do desenvolvimento sustentável e da busca de alternativas produtivas que possam possibilitar o equilibro entre os aspectos econômicos e ambientais, a apicultura brasileira reúne alguns requisitos que a coloca num elevado potencial de inclusão, pois, sob o ponto de vista ambiental, econômico e social, é capaz de gerar ocupaçōes "socialmente justas" (VIEIRA e RESENDE, 2006).

\subsection{As políticas públicas}

O objetivo de uma política pública deve ser direcionado para o atendimento da construção de um ambiente local adequado e propicio ao desenvolvimento, aspecto que primordialmente deve ser conduzido por uma escala. Nesse contexto Costa e Montenegro (2007) apontam alguns elementos que devem estar considerados: (i) a introdução de mecanismos facilitadores da difusão das inovaçôes, sejam estas radicais ou mesmo incrementais, nos métodos e nas organizaçóes; (ii) o apoio à organização de sistemas produtivos flexíveis e competitivos, com atenção especial para a construçáo de um ambiente adequado à boa relação entre empresas, fornecedores e clientes; (iii) a visão da cidade como um ambiente em constante transformação e como base para a ação competitiva, sendo o espaço por excelência do desenvolvimento endógeno, na medida em que é o território onde se criam e desenvolvem os novos espaços industriais e de serviços, devido às potencialidades de desenvolvimento e à capacidade de gerar externalidades; (iv) a percepção de que o processo de desenvolvimento não se dá no espaço abstrato, mas é condicionado por questóes de ordem cultural, institucional e política.

Para Muller e Surel (2004), há alguns elementos que contribuem para uma definição de uma política pública: (i) constitui um quadro normativo de ação; (ii) combina elementos de força pública e elementos de competência [expertise]; (iii) tende a constituir uma ordem local.

A construção de uma política pública envolve mais que um conjunto de decisóes; ela envolve atores sociais (políticos, funcionários de todos os níveis, grupos de interesses etc.) que constroem uma ordem local (Costa e Montenegro 2007). Como mencionam Muller e Surel (2004), citando Friedberg (1993), uma ordem social é uma "construção política relativamente autônoma que opera, em seu nível, a regulação dos conflitos entre os interessados, e assegura entre eles a articulação e a harmonização de seus interesses e seus fins individuais, assim como dos interesses e fins coletivos". Portanto, é importante analisar o conjunto dos atores que são afetados/beneficiados pela açáo do Estado, considerando que a participação deles na elaboração e na implementação da política pública ocorre de forma e graus variados.

Para Costa e Montenegro (2007), o início ou o fim de uma política pública não são, de antemão, claramente definidos, como também os objetivos da ação pública podem não estar explícitos ou antecipados. Uma política pública não é um dado, mas uma construção de pesquisa. 


\subsection{A legislaçáo e iniciativas nacionais relacionadas à apicultura no Brasil}

O mel após a colheita, conforme aponta Araújo, Silva e Sousa (2006), continua sujeito às modificaçôes físico-químicas, microbiológicas e sensoriais, aspectos que exigem produçóes dentro de níveis elevados de qualidade, controlando todas as etapas do seu processamento visando assim a garantir produtos de melhor qualidade. Nesse contexto a atividade apícola nacional tem algumas legislaçóes que buscam, em sua maior totalidade, assegurar as boas práticas de saúde com foco na qualidade do produto apícula.

As etapas do processo de produção do mel e o domínio da operacionalização de cada uma dessas etapas apresentam uma dependência do conhecimento dos principais critérios e indicadores da qualidade, bem como da legislação nacional vigente. A avaliaçáo das principais legislaçôes que normatizam a apicultura no território nacional apresentadas na Tabela 2, permite identificar que temos uma legislação com foco de comando e controle de processos.

Tabela 2 - Legislaçôes que normatizam a apicultura no território brasileiro

\section{Portaria no 6, de 25 de julho de 1985}

\section{Tipo de legislaçáo \\ Descriçáo}

Aprova as Normas Higiênico-Sanitárias e Tecnológicas para Mel, Cera de Abelhas e Derivados.

Instruçáo Normativa no 3, de 19 de janeiro de 2001

Aprova os Regulamentos Técnicos de Identidade e Qualidade de Apitoxina, Cera de Abelha, Geleia Real, Geleia Real Liofilizada, Pólen Apícola, Própolis e Extrato de Própolis.

Portaria no 9, de 18 de fevereiro de 2003

Institui o Comitê Científico Consultivo em Sanidade Apícola - CCCSA, que terá por finalidade oferecer subsídios técnico-científicos ao Departamento de Defesa Animal - DDA, para elaboração de normas e procedimentos relacionados à sanidade do plantel apícola brasileiro e à importação de abelhas e produtos apícolas.

Instruçáo Normativa no 16, de 11 de junho de 2004

Estabelece os procedimentos a serem adotados, até que se concluam os trabalhos de regulamentaçáo da Lei no 10.831, de 23 de dezembro de 2003, para registro e renovaçáo de registro de matérias-primas e produtos de origem animal e vegetal, orgânicos, junto ao Ministério da Agricultura, Pecuária e Abastecimento - MAPA.

Decreto No 5.741, de 30 de março de 2006

Regulamenta os arts. 27-A, 28-A e 29-A da Lei no 8.171, de 17 de janeiro de 1991, organiza o Sistema Unificado de Atenção à Sanidade Agropecuária, e dá outras providências.

Instruçáo Normativa no 64, de 19 de dezembro de 2008, do Ministério da Agricultura, Pecuária e Abastecimento (MAPA)

Aprova o Regulamento Técnico para os Sistemas Orgânicos de Produção Animal e Vegetal.

Resoluçáo no 001/2010, de 10 de abril de 2010

Regulamenta o Cadastro Nacional de Apicultor com vistas à emissão da Carteira Nacional de Apicultor. A Carteira Nacional de Apicultor servirá de documento de identificação e obtenção de desconto na participação dos congressos, assembleias e eventos nacionais de apicultura.

Decreto No 7.216, de 17 de junho de 2010

Dá nova redação e acresce dispositivos ao Regulamento dos arts. 27-A, 28-A e 29-A da Lei no 8.171, de 17 de janeiro de 1991, aprovado pelo Decreto no 5.741, de 30 de março de 2006, e dá outras providências. O Sistema Unificado de Atenção à Sanidade Agropecuária respeitará as especificidades regionais de produtos e das diferentes escalas de produção, incluindo a agroindústria rural de pequeno porte.

Fonte: Instruções, Decretos, Portarias e Resoluçáo. 
Quanto aos incentivos para o segmento apícula, programas como Programa Nacional voltado para Agricultura Familiar (PRONAF) e mais alimento (MDA- Secretaria de Desenvolvimento Agrário) oferecem acesso a recursos para aquisição de equipamentos.

Conforme destaca Bayle (2015), há algumas iniciativas realizadas no Brasil referentes à apicultura que merecem destaque:

Foi elaborado pela Confederação Brasileira de Apicultura o programa 'Meu dia pede mel' de divulgaçáo do consumo e usos do mel a partir de uma parceria com o Sebrae, a Fundação Banco do Brasil (BAYLE, 2015, p. 34).

Seguindo uma tendência mundial, o consumidor brasileiro busca, cada vez mais, saber a origem dos produtos que consome, identificando onde, e por quem são produzidos. Foi nesta perspectiva que foi definido e está sendo implantado o Programa Nacional de Georreferenciamento e Cadastro de Apicultores, o qual denominamos PNGEO. Ele tem como objetivo principal promover o Georreferenciamento, a Rastreabilidade e Modernizaçáo da Produção Apícola no Brasil, através de açôes de mapeamento, diagnóstico, capacitação e regulamentação das atividades em todos os elos da cadeia. Assim cada apiário no país terá sua demarcação geográfica realizada através de coleta do sistema GPS, permitindo assim a formação de um banco de dados nacional. O Pará é um dos primeiros Estados da federação a iniciar este trabalho realizado em campo com a parceria das equipes da Emater-PA, da Sagri, da CBA e da Fapic. O levantamento iniciou na regiāo Nordeste do Estado e está em andamento (BAYLE, 2015, p. 35).

\subsection{O perfil do apicultor brasileiro e sua produçáo}

Em 2001, quando se intensificaram as exportaçóes de mel para a Europa e Estados Unidos, iniciou nova etapa para a apicultura brasileira apontando para a exigência de novo perfil dos apicultores brasileiros (PAULA 2014). Conforme aponta o Sebrae, até o ano de 2001 a produção apícola tinha seu consumo centralizado no mercado nacional. A partir de então a criação de abelhas constituiu-se em uma relevante atividade agropecuária com a geração complementar, com maior destaque para muitas famílias de pequenos e médios produtores rurais, as quais, na sua maioria trabalham com a denominada apicultura fixa, em que as colmeias permanecem na mesma área no decorrer de anos.

A maioria dos apicultores brasileiros tem 20 colmeias em média e as atividades apícolas são realizadas pela própria família, destaca Pegararo (2013) apud Paula (2014). Há um volume expressivo de pequenos apicultores no país que exploram até 150 colmeias utilizando apenas a mão de obra familiar e ainda realizam outras atividades paralelas, podendo por vezes a apicultura ser a atividade secundária, fato que diferencia a atividade apícula brasileira. Há também na composição do perfil dos produtores apículas aqueles com a produção especializada e com maior utilização de capital, caracterizada pela exploração de 150 a 2.500 colmeias (Brasil 2007).

Segundo estimativa da Associação Brasileira de Apicultura (ABEMEL, 2013) há aproximadamente 350 mil apicultores no país, sendo a maioria relacionada com a agricultura familiar, os quais correspondem a 450 mil ocupaçóes diretas no campo. 
Observadas a pequena exigência de investimentos, a não exigência de mão de obra exclusiva, as condiçôes de adaptabilidade climática as regióes, baixos custos e possibilidade de geração de renda extra e melhoria das condiçóes de vida familiar à apicultura torna-se uma alternativa para muitas famílias de agricultores (SOUZA, 2007).

A apicultura brasileira tem como predomínio, aponta Pegararo (2013) apud Paula (2014), a forma artesanal no que diz respeito ao manuseio, coleta, envasamento e transporte. A casa do mel, denominação das propriedades ou associaçóes dos produtores apícolas, como destaca Pegararo (2013) apud Paula (2014), possuem equipamentos e utensílios básicos utilizados para o beneficiamento do produto. Esses lugares apresentam limitadas condiçóes de qualidade.

A Associação Brasileira de Mel (ABEMEL, 2013) destaca que a produção do Brasil por colmeia é de 15 a $20 \mathrm{~kg} / \mathrm{ano}$, volume que é considerado baixo quando comparado com a média de produção de outros países, como: Argentina, que produz de 35 a $40 \mathrm{~kg} /$ ano, o México com uma produção média de $25 \mathrm{~kg} / \mathrm{ano}$ e a China que chega até $50 \mathrm{~kg} / \mathrm{ano}$ por colmeia. Destaca-se que o principal fator que compromete a produtividade brasileira está relacionado ao manejo inadequado e à profissionalização, aspectos que, se trabalhados, podem elevar a média de produção para algo próximo a $40 \mathrm{~kg} / \mathrm{ano}$ por colmeia.

\subsection{A importância econômica da apicultura no Brasil}

O mercado mundial dos produtos apícolas, principalmente o mel, é rigoroso e os grandes consumidores têm padróes elevados de exigência. A crescente regulamentação do mercado reduz o espaço para novos produtores que vislumbram atender às normas técnicas, oriundos de países em desenvolvimento que apresentam frágeis infraestruturas de produção, comercialização e vigilância sanitária (BRASIL, 2007). No entanto, em 2002 aconteceu um fato marcante para o mercado apícola mundial, quando China e Argentina, os principais fornecedores de mel até então, tiveram suas exportaçóes suspensas pela Comunidade Europeia. Esse fato permitiu que países considerados emergentes no mercado exportador, como o Brasil, fossem inseridos na cadeia de exportação do mel, destaca Pires (2011).

O potencial apícola do Brasil, observados sua abundante área florestal e seu clima tropical, aponta para uma relevante oportunidade de mercado, contudo, apesar dos esforços públicos e privados para expansão desta atividade, ainda se encontra subexplorada. Ressaltase também que, a distribuição da produção nacional apresenta ainda relevante distância de volume produzido por estado, aspecto que aponta a oportunidade de um alinhamento do manejo, bem como uma análise mais minuciosa do impacto dos diferentes climas e plantas na produção do mel. Costa e Montenegro (2007) apontam também o conhecimento a respeito dos benefícios que o mel propicia à sociedade, à economia e ao meio ambiente como um dos fatores influentes na dinâmica de produção dos produtos apícolas.

Desde então, o Brasil passou a desempenhar um papel de destaque no mercado mundial do mel - os dados disponíveis sobre a produção posiciona o Brasil como o $11^{\circ}$ produtor no ranking mundial (TABELA 3). 
Tabela 3 Principais países produtores e quantidades de mel (em ton.) no período de 2008 a 2012

\begin{tabular}{lcccccc}
\hline \multicolumn{1}{c}{ Países } & $\mathbf{2 0 0 8}$ & $\mathbf{2 0 0 9}$ & $\mathbf{2 0 1 0}$ & $\mathbf{2 0 1 1}$ & $\mathbf{2 0 1 2}$ & Ranking 2012 \\
\hline China & 400.000 & 402.000 & 401.000 & 431.000 & 436.000 & $1^{\text {o }}$ \\
Turquia & 81.364 & 82.003 & 81.115 & 94.245 & 88.162 & $2^{\text {o }}$ \\
Argentina & 72.000 & 62.000 & 59.000 & 74.000 & 75.500 & $3^{\circ}$ \\
Ucrânia & 74.900 & 74.100 & 70.873 & 40.311 & 70.134 & $4^{\text {o }}$ \\
E.U.A. & 74.293 & 66.413 & 80.042 & 67.294 & 66.720 & $5^{\text {o }}$ \\
Rússia & 57.440 & 53.598 & 51.535 & 60.010 & 64.898 & $6^{\text {o }}$ \\
Índia & 55.000 & 55.000 & 60.000 & 60.000 & 61.000 & $7^{\circ}$ \\
México & 55.271 & 56.071 & 55.684 & 57.783 & 58.602 & $8^{\text {o }}$ \\
Iran & 41.000 & 46.000 & 47.000 & 47.000 & 48.000 & $9^{\circ}$ \\
Etiópia & 42.000 & 41.525 & 53.675 & 39.892 & 45.905 & $1^{\text {o }}$ \\
Brasil & $\mathbf{3 7 . 7 9 2}$ & $\mathbf{3 8 . 9 7 4}$ & $\mathbf{3 8 . 0 1 7}$ & $\mathbf{4 1 . 6 0 4}$ & $\mathbf{3 3 . 5 7 1}$ & $\mathbf{1 1}^{\mathbf{o}}$ \\
\hline
\end{tabular}

Fonte: FAOSTAT (2013).

O volume total de produção de mel do país no ano de 2012 decaiu 19,25\% em relação ano de 2011, aspecto que compromete as tendências econômicas e de desenvolvimento para o segmento. Contudo é possível observar que as maiores perdas estão centralizadas nas regiōes Norte e Nordeste, apontando assim para regióes que exigem uma prioridade de políticas publicas e privadas que contribuam com o incremento da produção e a devida comercialização, promovendo a apicultura e seu potencial para o desenvolvimento sócioeconômico dos atores envolvidos.

Tabela 4: Produção de mel de abelhas por estado brasileiro (em ton.) período de 2008 a 2012

\begin{tabular}{lccccc}
\hline Estados & $\mathbf{2 0 0 8}$ & $\mathbf{2 0 0 9}$ & $\mathbf{2 0 1 0}$ & $\mathbf{2 0 1 1}$ & $\mathbf{2 0 1 2}$ \\
\hline Rio Grande do Sul & 7.418 & 7.155 & 7.098 & 6.985 & 6.774 \\
Paraná & 4.635 & 4.831 & 5.468 & 5.179 & 5.496 \\
Santa Catarina & 3.796 & 4.515 & 3.966 & 3.990 & 4.389 \\
Minas Gerais & 2.862 & 2.606 & 3.076 & 3.076 & 3.399 \\
São Paulo & 2.017 & 2.104 & 2.261 & 2.229 & 2.464 \\
Ceará & 4.073 & 4.735 & 2.706 & 4.165 & 2.017 \\
Bahia & 2.195 & 1.922 & 2.397 & 2.646 & 1.595 \\
Piauí & 4.144 & 4.278 & 3.262 & 5.198 & 1.563 \\
Maranhão & 781 & 748 & 1.119 & 1.107 & 1.108
\end{tabular}




\begin{tabular}{|c|c|c|c|c|c|}
\hline Estados & 2008 & 2009 & 2010 & 2011 & 2012 \\
\hline Mato Grosso do Sul & 646 & 430 & 512 & 686 & 821 \\
\hline Pernambuco & 1.382 & 1.595 & 2.094 & 2.350 & 636 \\
\hline Espírito Santo & 331 & 367 & 468 & 463 & 487 \\
\hline Pará & 397 & 355 & 402 & 414 & 436 \\
\hline Rio Grande do Norte & 1.065 & 1.107 & 886 & 904 & 406 \\
\hline Mato Grosso & 494 & 315 & 428 & 379 & 406 \\
\hline Rio de Janeiro & 315 & 318 & 351 & 383 & 377 \\
\hline Goiás & 322 & 301 & 315 & 334 & 315 \\
\hline Paraíba & 222 & 273 & 270 & 303 & 188 \\
\hline Rondônia & 161 & 168 & 172 & 185 & 176 \\
\hline Alagoas & 155 & 169 & 203 & 213 & 134 \\
\hline Roraima & 133 & 133 & 134 & 132 & 132 \\
\hline Tocantins & 135 & 130 & 156 & 153 & 125 \\
\hline Sergipe & 136 & 137 & 125 & 114 & 54 \\
\hline Amazonas & 19 & 21 & 45 & 48 & 43 \\
\hline Distrito Federal & 36 & 38 & 35 & 16 & 20 \\
\hline Amapá & 8 & 8 & 8 & 8 & 8 \\
\hline Acre & 5 & 6 & 5 & 5 & 6 \\
\hline Total & 37.792 & 38.765 & 38.017 & 41.578 & 33.574 \\
\hline
\end{tabular}

Fonte: IBGE (2013).

Importante ressaltar, neste sentido, que o mel não é uma commodity e, por isso, precisa de estratégia e política de promoção comercial, criação de marcas, desenvolvimento de identidade regional e local. Além disso, é fundamental a disponibilidade de políticas de crédito financeiro (capital de giro, tanto para produção quanto para processamento) alicerçada em pesquisas regionais para apoiar o arranjo produtivo, assim como a preparação dos profissionais e empresas ligado à apicultura nos aspectos estrutural, cultural e de gestão para obtenção da licença sanitária na esfera municipal, estadual e federal, focando atender as normas internacionais de fabricação e controle de qualidade.

\subsection{Arranjo Produtivo Local e a sua caracterização pelo agente público em Rondônia}

O Arranjo Produtivo Local (APL) pode ser conceituado como a presença de empresas em aglomerações, concentradas em um mesmo território, apresentando especialização produtiva e mantendo algum vínculo de articulação, interação, cooperação e aprendizagem entre si e outros atores locais, como: governo, associaçóes empresariais, instituiçóes de crédito, ensino e pesquisa (SEBRAE, 2006). 
Segundo Lastres e Cassiolato (2005), os APLs são aqueles casos fragmentados que não apresentam significativa articulação entre os agentes locais e que, portanto, não se caracterizam como sistemas. No Brasil a adequação desse conceito ganhou a denominação de arranjo produtivo local por apresentar vínculos incipientes, pois, nesse tipo de aglomeração, a organização empresarial se encontra ainda precária.

Os APLs agem em torno de uma atividade produtiva principal, abrangendo um território definido, e se organizam por meio de um sistema de governança local representativo, cuja proximidade geográfica facilita a redução de custos de transporte, de estoques, da formação de mão de obra, entre outros. A formação de APLs geralmente é agregada à construção de identidades históricas semelhante, e apresenta uma análise que vai além da organização individual (SILVEIRA, 2007).

Os APLs têm um papel fundamental no desenvolvimento econômico, social e tecnológico de uma região, destaca SILVEIRA (2007), beneficiando empresas e engajando comunidades locais, centros de tecnologia e pesquisa, instituiçóes de ensino e entidades públicas ou privadas. Tudo isso possibilita a inserção das empresas em novos mercados, inclusive os externos. Além disso, as empresas instaladas em APLs podem exercer o aprendizado coletivo, a troca de informaçôes, a eficiência coletiva e o aumento da competitividade.

Ainda, conforme o autor supracitado, para que os arranjos produtivos evoluam e passem para o estágio de sistemas produtivos locais, é fundamental a formação de uma boa governança, destacando-se dois tipos: horizontal ou em redes e vertical ou hierárquica. $\mathrm{Na}$ governança horizontal encontram-se as pequenas empresas, na maioria, sem a presença de empresas maiores instaladas no local capazes de exercer o papel de coordenadora das atividades.

$\mathrm{Na}$ tipologia de governança vertical, as grandes empresas desempenham a função de âncora na economia local, estabelecendo relaçóes com fornecedores locais e criando um ambiente de cooperação. Entretanto, o desenvolvimento da governança de forma integrada, consistente e sustentável é um mecanismo importante para que um arranjo produtivo passe a ser considerado como um sistema produtivo local.

Para o estado de Rondônia, a criação do Núcleo Estadual de Apoio aos Arranjos Produtivos Locais (NEAPL/RO) a partir de 2008 sinalizou para uma preocupação pública com o mapeamento e o desenvolvimento dos arranjos produtivos do estado. Em 2012 o Núcleo Estadual de Apoio aos Arranjos Produtivos Locais de Rondônia (NEAPL/RO) definiu os arranjos produtivos em desenvolvimento no estado e suas localizaçóes, conforme Tabela 5 . 
Tabela 5: Arranjos Produtivos Locais (APLs) priorizadas para o estado de Rondônia até o ano de 2012

\begin{tabular}{ccc}
\hline $\mathbf{N o}$ & APL & Município polo \\
\hline $\mathbf{1}$ & APL Apicultura & Vilhena \\
$\mathbf{2}$ & APL Piscicultura & Pimenta Bueno \\
$\mathbf{3}$ & APL Piscicultura & Ariquemes \\
$\mathbf{4}$ & APL Pecuária de Leite & JI - Paraná \\
$\mathbf{5}$ & APL SAFs & Ouro Preto \\
$\mathbf{6}$ & APL Madeira Móveis & Ariquemes \\
$\mathbf{7}$ & APL Fruticultura & Porto Velho \\
$\mathbf{8}$ & APL Confecção de Pimenta Bueno/Cacoal & Pimenta Bueno \\
$\mathbf{9}$ & APL Cafeicultura de Cacoal* & Cacoal \\
$\mathbf{1 0}$ & APL Hortigranjeiro em Porto Velho* & Porto Velho \\
$\mathbf{1 1}$ & APL Turismo & Guajará Mirim \\
$\mathbf{1 2}$ & APL Fruticultura Cacoal/Rolim de Moura** & Cacoal \\
$\mathbf{1 3}$ & APL da Sociobiodiversidade da Região do Mamoré** & Guajará Mirim \\
\hline
\end{tabular}

* APLs incluídas em reunião do NEAPL, em 2008.

** APLs inseridas em 2012.

Fonte: PLANEJAMENTO DO NEAPL RO - 2013.

\section{MATERIAL E MÉTODOS}

Para alcançar o objetivo proposto na presente pesquisa, o método adotado foi a pesquisa documental, que, segundo Lakatos e Marconi (2006), é um conjunto de preceitos ou processos de que se serve uma ciência ou artigo; é habilidade para usar esses preceitos ou normas, a parte prática. Para esse estudo, procedemos com a coleta de dados escritos primários e secundários contemporâneos com base na análise de documentos públicos e censos estatísticos governamentais.

Compondo a análise documental, a coleta foi estruturada conforme Figura 1. 
Figura 1: Framework das etapas de análise documental

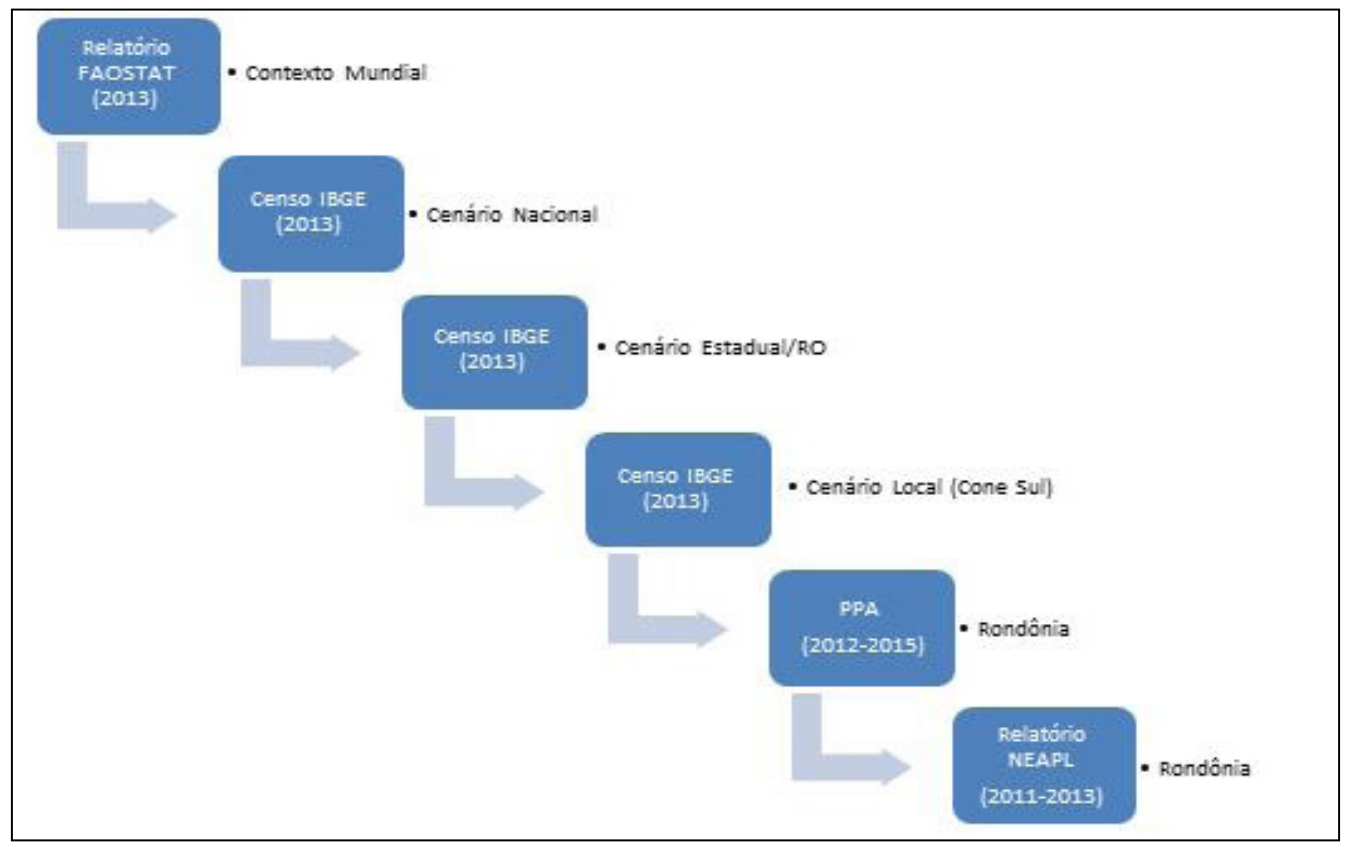

Fonte: Elaborada pelos autores.

A categorização das informaçóes obtidas com a análise de documentos foi realizada no intuito de orientar a análise de conteúdo definida por Bardin (2011) como uma operação ou um conjunto de operaçóes visando a representar o conteúdo de um documento, sob uma forma diferente da original, a fim de facilitar, num estado ulterior, a sua consulta e referenciação. Desse modo, as características dos escritos sobre o censo e demais relatórios apresentados na Figura 1 visam a facilitar o entendimento das políticas públicas relacionadas ao cenário apícola focado no estado de Rondônia.

\section{ANALISE E DISCUSSÓES}

\subsection{Dinâmica do cenário apícola rondoniense}

A apicultura rondoniense, conforme aponta o plano de desenvolvimento preliminar do arranjo produtivo da apicultura em Vilhena, estado de Rondônia, foi iniciada no final da década de 70 com a chegada dos migrantes do sul do país. Esses colonos, com tradição da atividade em seus estados de origem, implantaram os primeiros apiários comerciais em Rondônia, na região de Vilhena.

$\mathrm{Na}$ década de 80, a apicultura foi implementada por meio de capacitação técnica e investimentos em infraestrutura pelo Governo do Estado, por meio do Plano Agropecuário e Florestal de Rondônia (Planafloro). Em 2004, o arranjo produtivo local (APL) recebeu novo impulso com investimentos que o Sebrae/RO e parceiros fizeram no setor quando 
teve início o Projeto de Apicultura Integrada e Sustentável (Proapis), consolidando assim a atividade apícola na regiấo Sul do estado de Rondônia, com os municípios de Vilhena, Colorado do Oeste, Cerejeiras, Cabixi, Chupinguaia, Pimenteiras e Corumbiara.

No ano de 2008, por meio do Decreto Estadual no 13.666, de 16 de junho, foi criado o Núcleo Estadual de Apoio aos Arranjos Produtivos Locais de Rondônia, estabelecendo um interesse de implementaçôes de políticas públicas para o fomento dos arranjos produtivos do Estado, sendo a apicultura um dos elementos de produção classificado como arranjo produtivo do estado (SOUZA, 2010).

Em Rondônia, a apicultura ainda está em processo dinâmico de desenvolvimento, sendo a regiáo do Cone Sul do estado, liderada pelas cidades de Vilhena, Cerejeiras e Colorado do Oeste, a que mais se destaca em termos de produçáo. De acordo com os dados levantados no Instituto Brasileiro de Geografia e Estatística (IBGE), o Cone Sul do Estado de Rondônia foi responsável pela maior produçáo de mel em todo o estado no ano de 2012 (TABELA 6).

Tabela 6: Dados representativos da produção de mel no Cone Sul em comparação à produção total do estado de Rondônia entre os anos de 2008 e 2012

\begin{tabular}{|c|c|c|c|c|c|}
\hline \multirow[b]{2}{*}{ Estado e município } & \multicolumn{5}{|c|}{ Quantidade de mel produzido no período (quilos) } \\
\hline & 2008 & 2009 & 2010 & 2011 & 2012 \\
\hline $\begin{array}{l}\text { Produção Cone Sul do Estado de } \\
\text { Rondônia }\end{array}$ & 57.608 & 68.829 & 78.144 & 93.074 & 94.382 \\
\hline $\begin{array}{l}\text { Produção dos demais municípios do } \\
\text { Estado de Rondônia }\end{array}$ & 102.992 & 99.574 & 93.846 & 91.696 & 81.291 \\
\hline $\begin{array}{l}\text { Produção total do estado de } \\
\text { Rondônia }\end{array}$ & 160.600 & 168.403 & 171.990 & 184.770 & 175.673 \\
\hline $\begin{array}{l}\text { \% de produção do Cone Sul do } \\
\text { Estado de Rondônia }\end{array}$ & $35,87 \%$ & $40,87 \%$ & $45,44 \%$ & $50,37 \%$ & $53,73 \%$ \\
\hline $\begin{array}{l}\text { \% de produçáo dos demais } \\
\text { municípios do Estado de Rondônia }\end{array}$ & $64,13 \%$ & $59,13 \%$ & $54,56 \%$ & $49,63 \%$ & $46,27 \%$ \\
\hline
\end{tabular}

Fonte: IBGE (2013).

A maior produção observada no Território de Identidade do Cone Sul no estado pode estar refletindo as ações de políticas públicas iniciadas na região, como a seleção da apicultura como prioridade de arranjo produtivo local, tendo como cidade polo o município de Vilhena (NEAPL/RO, 2013). Destaca-se, nesse processo, a ocupaçáo do estado, sendo o Cone Sul uma regiáo habitada por colonos ligados culturalmente à atividade apícola em seus estados de origem. Além disso, a regiáo possui uma vegetação de transição, caracterizada por uma grande diversidade vegetal, possuindo áreas de domínios dos cerrados do Brasil Central e da floresta Amazônica, além de vastas áreas de cultivo agrícola (MIRANDA et al., 2006), que são utilizadas como recurso para a produção de mel.

Para o estado de Rondônia, a criação do Núcleo Estadual de Apoio aos Arranjos Produtivos Locais (NEAPL/RO) a partir de 2008 sinalizou para uma preocupação pública 
com o mapeamento e o desenvolvimento dos arranjos produtivos do estado. Em 2012 o Núcleo Estadual de Apoio aos Arranjos Produtivos Locais de Rondônia (NEAPL/RO) definiu os arranjos produtivos em desenvolvimento no estado e suas localizaçóes, conforme Tabela 5 .

O NEAPL/RO, na $1^{\text {a }}$ reunião ordinária realizada no ano de 2013, aprovou um plano de ação para atendimento aos arranjos produtivos. Esse plano de ação visou a apoiar os arranjos produtivos do estado, sendo priorizados, inicialmente, apenas cinco arranjos produtivos locais (APLs), dentre os quais a apicultura é considerada uma das principais atividades, juntamente com a piscicultura, confecção, sociobiodiversidade e pecuária de leite.

O plano de políticas públicas do estado para atendimento aos arranjos produtivos priorizados foram categorizados em atividades de gestão, capacitação, identificação e observatório.

As etapas previstas de Gestão do Núcleo Estadual de Apoio aos Arranjos Produtivos Locais são: i) o gerenciamento do NEAPL/RO propriamente dito, tendo como uma das tarefas a criação e a elaboração de mecanismos, documentos relacionados ao funcionamento do NEAPL e APLs, e promoção e participação de reuniōes, palestras, seminários e cursos e outros eventos; ii) definição de responsabilidade institucional dos APLs, iii) monitoramento - destaca-se a tarefa de realizar e definir instrumentos de monitoramento e acompanhamento das APLs. Na Capacitação, treinamento e divulgação para os Arranjos Produtivos Locais, configuram-se as etapas: i) produção de material informativo; ii) realização do primeiro curso de formuladores e executores de políticas de APL, carga horária: 24 horas-aula, para 40 participantes; iii) realização de primeiro curso de gestores e de multiplicadores de APLs, com carga horária de 24 horas-aula, para 40 participantes; iv) realização de dois seminários, organização e gestão de APLs; e v) participação na 6a Conferência Brasileira de APL.

Nas atividades de Identificação e Organização dos Arranjos Produtivos Locais encontramse as etapas: i) cadastro e atualização dos APLs; ii) cadastro de contratos; iv) apoio técnico para os APLs; v) formação e fortalecimentos dos comitês gestores; vi) formação dos planos de desenvolvimento. O Observatório para os Arranjos Produtivos Locais apresenta as seguintes etapas: i) instituir câmara técnica para os observatórios de APLs; ii) treinar pessoal; iii) coletar dados; iv) inserir dados no portal APL, nas redes sociais e outros; v) avaliar e adequar sistemas.

O planejamento plurianual do governo do estado de Rondônia para o período de 2012 a 2015 apresenta recursos a serem aplicados em favor dos arranjos produtivos priorizados que estão distribuídos em modernização da gestão apoiada, perfazendo um total de R\$ 1.500.000,00, e observatório econômico e social com um total de R $\$ 1.500 .000,00$ (PPA GOVERNO DE RONDÔNIA 2012 a 2015). As açóes para atividades de modernização da gestão apoiada com foco nos arranjos produtivos propostos no plano plurianual envolvem a coordenação, acompanhamento, promoção e integração de projetos regionais, visando ao fomento e ao desenvolvimento dos APLs. Já as açóes para o observatório econômico e social desenvolvido com foco nos arranjos produtivos propostos no plano plurianual envolve cooperação empresarial e a inovação por meio da capacitação e orientação técnica para os Arranjos Produtivos Locais (PPA GOVERNO DE RONDÔNIA 2012 a 2015). 
Observam-se poucas atividades realizadas com os Arranjos Produtivos Locais do estado de Rondônia relacionados às políticas públicas. O Quadro 2 informa as atividades realizadas nos anos de 2011 a 2013.

Quadro 1: Atividades da NEAPL/RO 2011 a 2013

\begin{tabular}{|c|c|c|}
\hline ANO & ATIVIDADES & ABRANGÊNCIA/REALIZAÇÓES \\
\hline \multirow{2}{*}{2011} & $\begin{array}{l}\text { Formaçáo de três } \\
\text { grupos regionais de } \\
\text { APLs }\end{array}$ & $\begin{array}{l}\text { a. Grupo Regional de APL Mamoré - Região X } \\
\text { b. Grupo Regional de APL Rolim de Moura - Região VIII } \\
\text { c. Grupo Regional de APL de Ji-Paraná - Região V } \\
\end{array}$ \\
\hline & $\begin{array}{l}\text { Realização de três } \\
\text { seminários }\end{array}$ & $\begin{array}{l}\text { I Seminário Estadual - Capacitação em Organização e Gestão de } \\
\text { Arranjos Produtivos Locais nas cidades de Guajará Mirim, Rolim de } \\
\text { Moura, Ji-Paraná (participantes: } 178 \text { ) }\end{array}$ \\
\hline \multirow{4}{*}{2012} & $\begin{array}{l}\text { Cadastro de APLS } \\
\text { MDIC }\end{array}$ & $\begin{array}{l}\text { Preenchimento dos formulários para cadastro dos APLs, } \\
\text { Fruticultura Centro Sul de Rondônia, Confecção de } \\
\text { Pimenta Bueno e Cacoal, Turismo da Região do Mamoré, } \\
\text { Sociobiodiversidade da Região do Mamoré e encaminhamento ao } \\
\text { Ministério do Desenvolvimento, Indústria e Comércio. }\end{array}$ \\
\hline & $\begin{array}{l}\text { Organização de } \\
\text { APLS }\end{array}$ & $\begin{array}{l}\text { Formação de quatro grupos regionais de APLs: } \\
\text { a. Grupo Regional de APL Mamoré - Região X } \\
\text { b. Grupo Regional de APL Rolim de Moura - Região VIII } \\
\text { c. Grupo Regional de APL de Ji-Paraná, Região V } \\
\text { d. Grupo Regional de APL de Cacoal } \\
\text { e. Realização de reunióes em Guajará Mirim para formação dos } \\
\text { comitês gestores dos APLs da sociobiodiversidade e do turismo. }\end{array}$ \\
\hline & $\begin{array}{l}\text { Câmara técnica de } \\
\text { fruticultura }\end{array}$ & $\begin{array}{l}\text { Promoçáo de desenvolvimento da cadeia produtiva da fruticultura } \\
\text { de forma articulada com o setor público e privado, por meio de } \\
\text { proposiçóes que orientem a elaboraçáo e a execuçáo de políticas } \\
\text { públicas. }\end{array}$ \\
\hline & Plano de capacitação & $\begin{array}{l}\text { a. Realização do I Seminário Estadual “Capacitação em } \\
\text { Organização e Gestáo de Arranjos Produtivos Locais” - Cacoal. } \\
\text { b. Estruturação de cursos para capacitação em organização e } \\
\text { gestão de APLs } \\
\text { c. Elaboração de dois Termos de Referência para contratação de } \\
\text { cursos de APL. }\end{array}$ \\
\hline 2013 & Planejamento & 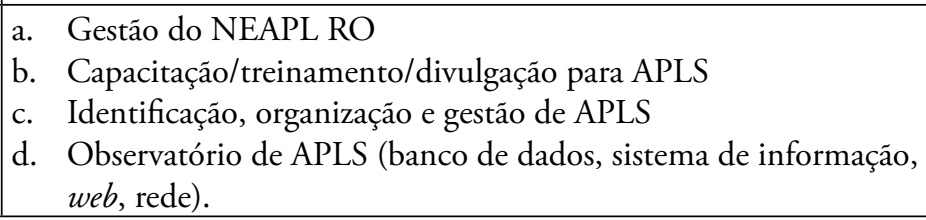 \\
\hline
\end{tabular}

Fonte: NEAPL/RO (2011; 2012 e 2013).

As projeções orçamentárias apresentadas para as políticas públicas relacionadas aos arranjos produtivos locais definidos como prioridade para o estado de Rondônia, tardia nas suas execuçóes, desconsideram, entretanto, as emergentes necessidades apresentadas pelos arranjos produtivos locais, entre os quais se destaca a apicultura; apresentam ausência de sincronia com a necessidade de redução das desigualdades sociais: não contêm projeção para 
o aumento da produção e da riqueza social com autonomia dos arranjos; têm limitação nos alvos de melhoria da qualidade de vida dos atores envolvidos com os arranjos produtivos locais; apresentam ausência de uma proposta de indicadores que possam ser aplicados para a medição da preservação do potencial natural na sua produção de recursos, aspecto muito forte no ambiente da apicultura; não preveem benefícios que equilibrem as atividades relacionadas aos arranjos produtivos, fortalecendo as atividades e valorizando a permanência dos agentes nos seus ambientes e incorporando-os no processo de desenvolvimento, e desconsideram as atividades inovadoras necessárias, observando as tradiçóes presentes nos arranjos.

\section{CONSIDERAÇÓES FINAIS}

A atividade apícola associa-se de maneira harmoniosa com a conservação ambiental, estando em consonância com as dimensóes social, econômica, ambiental, ecológica, territorial, política e cultural da sustentabilidade, sendo, portanto, uma alternativa viável para o desenvolvimento socioeconômico de regióes devastadas pelos processos de colonização recentes, marcados pelo desmatamento exacerbado e conflitos territoriais.

O mel não é uma commodity e, por isso, precisa de estratégia e política de promoção comercial, criação de marcas, desenvolvimento de identidade regional e local. Há ausência de políticas de crédito financeiro (capital de giro, tanto para produção quanto para processamento) alicerçadas em pesquisas regionais para apoiar o arranjo produtivo. Existe a necessidade de preparação dos profissionais e empresas ligadas à apicultura no aspecto estrutural, cultural e gestão para obtenção da licença sanitária na esfera municipal, estadual e federal focando atender às normas internacionais de fabricação e controle de qualidade. $\mathrm{O}$ desenvolvimento da atividade apícola em Rondônia tem sido uma realidade nos últimos dez anos e seus volumes de produção estão centralizados na regiáo Sul do estado.

As políticas públicas do estado de Rondônia precisam estar sincronizadas com as pesquisas sobre a apicultura e sustentabilidade. Sugere-se a observação dos elementos sustentáveis e das suas dimensóes que categorizam a apicultura como atividade que pode contribuir para redução das desigualdades sociais (sustentabilidade social); melhoria da qualidade ambiental e da manutenção do potencial do capital natural observada a preservação que é própria da atividade apícola (sustentabilidade ambiental e ecológica); equilíbrio de ambiente com a equiparação da atividade rural, observado que a maior parte das famílias envolvidas com a apicultura está localizada na área rural, aspecto que pode contribuir para a minimização da migração para as áreas suburbanas (sustentabilidade territorial); Possibilidade de inserção do apicultor no processo de desenvolvimento (sustentabilidade politica); equilíbrio entre respeito à tradição do apicultor e inovação exigida pela apicultura focando prepará-los para o mercado mundial (sustentabilidade cultural).

$\mathrm{O}$ estado de Rondônia revela um potencial produtivo e competitivo no mercado nacional do mel, sendo o Território de Identidade do Cone Sul uma região particularmente interessante para o desenvolvimento da referida atividade, pois, por suas qualidades ambientais, culturais, sociais e políticas, a região apresenta uma significativa contribuição para a produção de mel no estado. Entretanto, os esforços para apoiar essa atividade por 
meio de políticas públicas, como a proposta do Arranjo Produtivo Local planejado, desde 2013, e a destinação orçamentária para a apicultura como um dos arranjos prioritários para o estado, não apresentaram impactos significativos para a atividade apícola e carecem de maiores discussóes, principalmente no que se refere às peculiaridades de cada território atendido.

Os eventos realizados apontam para um princípio de discussão e construção de conceitos sobre Arranjo Produtivo Local, contudo apresentam fragilidade quando não focam as atividades específicas de cada arranjo definido como prioridade para o Estado.

$\mathrm{O}$ segmento de apicultura não recebe uma abordagem e ações específicas nas atividades realizadas no período de 2011 a 2013 e não está integrado ao planejamento público, pois muitos apicultores desconhecem o planejamento, orçamento e programaçóes de reuniōes voltadas para o segmento.

\section{REFERÊNCIAS}

ABEMEL - Associaçáo Brasileira dos Exportadores de Mel. 2013. Disponível em $<$ http://www.beebrazil.com/abemel.aspx>. Acesso em 02/02/14.

ARAÚJO, D.R.; SILVA, R.H.D.; SOUSA, J.S. Avaliaçáo da qualidade físico-química do mel comercializado na cidade de Crato, CE. Revista de Biologia e Ciências da Terra, v.6, n.1, 10 Semestre 2006.

BANERJEE, SUBHABRATA B. (2003). "Who Sustains Whose Development?

Sustainable Development and the Reinvention of Nature”. Organization Studies, 2003; no. 24; pp. 143-180.

BAYLE, EMMANUEL . Estudo Da Cadeia Produtiva do Mel no Estado Do Pará. Pará Rural. Desenvolvimento Sustentável. Disponível em http://www.pararural.pa.gov.br/ smipararural/site/conteudos/midias/3bc0e3e0e9c57a8a3c9162bbe138a653.pdf. Acesso em 14 de maio de 2016;

BRASIL. Ministério da Agricultura, Pecuária e Abastecimento. Cadeia produtiva de flores e mel. Brasília: IICA e MAPA/SPA, 2007. 140 p. (Agronegócios, v. 9).

BARDIN, LAURENCE. Análise de conteúdo. São Paulo: Ediçóes 70, 2011.

CAMARGO, J. M. F. (Org). Manual de apicultura, São Paulo, Ed. 1972, p. 19.

COSTA, G. C. DA.; MONTENEGRO, J. P. B. Análise dos canais de comercializaçáo da apicultura familiar do município de APODI - RN, no ano de 2005. Sociedade Brasileira de Economia, Administração e Sociologia Rural. 2007. Disponível em <http://65.54.113.26/Publication/10339484 >. Acesso em 10 jan. 2014.

DONAIRE, Denis. Gestáo Ambiental na empresa. São Paulo : Atlas, 1995. 
FAOSTAT (2013) http://faostat3.fao.org/faostat-gateway/go/to/search/miel/S.

GUIMARÁES, N. P. Apicultura, a ciência da longa vida. Ed. Itatiaia Ltda. Belo Horizonte, 1989.

IBGE. Instituto Brasileiro de Geografia e Estatística. Produçáo da pecuária municipal (2008 a 2012). 2013. Disponível em <ftp://ftp.ibge.gov.br/Producao_Pecuaria/

Producao_da_Pecuaria_Municipal/2013/ppm2013.pdf>. Acesso em 20 fev. 2015.

LASTRES, Helena M. M.; CASSIOLATO, José E. Mobilizando conhecimentos para desenvolver Arranjos e Sistemas Produtivos e Inovativos Locais de Micro e Pequenas Empresas no Brasil. Disponível em: <http://redesist.ie.ufrj.br/glossario.php>. Acesso em: 04 set. 2015 .

LAKATOS, E. M. \& MARCONI, M. A. Metodologia científica. $\otimes 4^{\text {a }}$ ed. São Paulo: Atlas, 2006.

LIMA, S. A. M. A apicultura como alternativa social, econômica e ambiental para a XI mesorregião do noroeste do Paraná. Dissertação Mestrado. Curso de Pós-graduação em Engenharia Florestal do Setor de Ciências Agrárias da Universidade Federal do Paraná. 2005. 96 p. Acesso em www.floresta.ufpr.br/pos-graduacao/defesas/pdf.../d442_0620-M. pdf em 30 jan. 2014.

MAPA. Ministério da Agricultura, Pecuária e Abastecimento. Cadeia produtiva de flores e mel. Secretaria de Política Agrícola, Instituto Interamericano de Cooperação para a Agricultura: Antônio Márcio Buainain e Mário Otávio Batalha (Coordenadores). Brasília: IICA MAPA/SPA, 140 p., 2007.

MACHADO, ELISABETE CHRISTINA MENDES; SILVA, DENISE CÁSSIA DA. As relaçóes entre o modelo de gestáo e o desenvolvimento socioeconômico de uma cooperativa de mel: um estudo e caso na COOPI em APODI - RN. Observatório Comercio Exterior. ANO 3, 2010. Vol. 1.

MIRANDA, I. S.; ALMEIDA, S. S.; DANTAS, P. J. Florística e estrutura de comunidades arbóreas em cerrados de Rondônia, Brasil. Acta Amazônica, v. 36, n. 4, 2006, p. 419-430.

MULLER, PIERRE; SUREL, YVES. A análise de políticas públicas, 2 ed., Pelotas (RS): Educat, 2004.

NEAPL/RO. Núcleo Estadual de Apoio Aos Arranjos Produtivos Locais de Rondônia. Planejamento do NEAPL/RO. Governo do Estado de Rondônia. Secretaria de Estado do Planejamento e Coordenação Geral. Gerência de Desenvolvimento e Políticas Públicas GPP. 2013.

NEAPL/RO. Núcleo Estadual de Apoio Aos Arranjos Produtivos Locais de Rondônia. Relatório de atividades NEAPL/RO. Governo do Estado de Rondônia. Secretaria de 
Estado do Planejamento e Coordenação Geral. Gerência de Desenvolvimento Políticas Públicas - GPP. 2011.

NEAPL/RO. Núcleo Estadual de Apoio Aos Arranjos Produtivos Locais de Rondônia. Relatório de atividades NEAPL/RO. Governo do Estado de Rondônia. Secretaria de Estado do Planejamento e Coordenação Geral. Gerência de Desenvolvimento e Políticas Públicas - GPP. 2012.

PAULA, MARISTELA FRANCHETTI DE. Desempenho das exportaçóes brasileiras de mel natural. Biblioteca de Ciências Florestais e da Madeira - UFPR. - 2014.

PIRES, R. M. C. Qualidade do mel de abelhas Apis mellifera Linnaeus. Teresina: 2011.

SIENA, Osmar et al. Busca da Sustentabilidade para os Produtos Náo-Madeiráveis (PFNM) para o Estado de Rondônia (RO). MCT/CNPq/CT-INFRA/CTPETRO/ AÇÁO TRANSVESSAL - IV. Porto Velho- RO, 2008.

SILVA, R.C.P.A.; PEIXE, B.C.S. Estudo da Cadeia Produtiva do Mel no Contexto da Apicultura Paranaense: uma Contribuição para a Identificação de Políticas Públicas Prioritárias. 10 Seminário de Políticas Públicas no Paraná. Anais. Curitiba, UFPR. p.4. 2008.

SILVEIRA, J. A. J. As estratégias de comercialização dos produtores de arroz no estado do rio grande do sul. 2007. 146 p. Dissertação Mestrado (Administração e Negócios). Pontifícia Universidade Católica do Rio Grande do Sul

SILVEIRA, M. S., Arranjo Produtivo Local: O estudo de Caso da Cerâmica Vermelha de Russas. Trabalho conclusáo de Curso de Graduação (Administração). Fortaleza: Universidade Federal do Ceará - UFC, 2007.48 p.

SOUZA, D. C. (Org.). Apicultura - manual do agente de desenvolvimento rural, SEBRAE. 2.ed. revisada. 2007, p. 7.

SEBRAE. Desafios da Apicultura Brasileira. Brasília, n. 3, 2006.

SOUZA, J. A. Estratégias que impactam o processo de comercialização dos apicultores: Cone Sul do Estado de Rondônia. Dissertação de Mestrado. (Administração). Universidade Federal de Rondônia - UNIR. 2010.

VIEIRA, M. I. Apicultura atual: abelhas africanizadas; melhor adaptaçáo ecológica, maior produtividade, maiores lucros. São Paulo. 1986, p. 11.

VIEIRA, ALZIRA; RESENDE, REGINALDO. APIS - Apicultura

Integrada e Sustentável. Sebrae. Disponível em: <http://www.sebrae.com.br/ exibeBia?id=81 \&searchterm=apicultura $>$. Acesso em: 15/12/2008. 